\title{
Nye antikoagulasjonsmidler i kombinasjon med platehemmere
}

\author{
De nye direkte antikoagulasjonsmidlene brukes i økende grad. Data \\ fra både kontrollerte studier og klinisk praksis har vist at disse medika- \\ mentene er like effektive og trygge som warfarin ved blant annet dyp \\ venetrombose og lungeembolisme og som slagprofylakse ved atrieflim- \\ mer. Men hva hvis det også er indikasjon for platehemming? Her disku- \\ teres platehemming i kombinasjon med nye antikoagulasjonsmidlene \\ ved ulike indikasjoner.
}

De nye perorale antikoagulasjonsmidlene på engelsk «non-vitamin $\mathrm{K}$ oral anticoagulants» eller «direct oral anticoagulants», som på norsk forkortes NOAK eller DOAK - er inkludert i retningslinjene for tromboseprofylakse etter hofte- og kneleddskirurgi, til forebygging og behandling av venøs tromboembolisme (dyp venetrombose og lungeembolisme), til forebygging av hjerneinfarkt og TIA ved atrieflimmer samt som sekundærprofylakse etter hjerteinfarkt (1). Apiksaban, rivaroksaban og dabigatran er de tre nye preparatene som foreløpig er godkjent for bruk i Norge. Edoksaban er godkjent i Europa, men foreløpig ikke markedsført i Norge (forventet fra ultimo 2016).

Siden det ikke foreligger noen randomiserte studier av blødningsrisikoen ved bruk av de nye midlene $\mathrm{i}$ kombinasjon med platehemmere, er kunnskapsgrunnlaget for slik behandling basert på posthocanalyser av fase 3-studier og ekspertenes konsensus. Vi vil gjennomgå kunnskapsgrunnlaget og sikkerheten ved kombinasjonsbehandling for de aktuelle indikasjonene.

Artikkelen er basert på norske, europeiske og amerikanske retningslinjer (1-4), søk i PubMed etter artikler publisert fra 1980 til november 2015 med kombinasjoner av relevante emneord, søk i artikkelforfatternes egne litteraturarkiv og vår kliniske erfaring. Flere av forfatterne har vært delaktige $i$ arbeidet med de europeiske og de norske retningslinjene for bruk av nye antikoagulasjonsmidler $(4,5)$.

\section{Forebygging av hjerneinfarkt og TIA ved atrieflimmer}

For pasienter med atrieflimmer og minst to risikofaktorer for tromboembolisme $\left(\mathrm{CHA}_{2} \mathrm{DS}_{2}\right.$ VASc-skår $\geq 2$ ) anbefales livslang antikoagulasjonsbehandling. Hos dem med kun én risikofaktor $\left(\mathrm{CHA}_{2} \mathrm{DS}_{2}\right.$-VASc-skår $\left.=1\right)$ bør det gjøres en individuell vurdering. Kvinnelig kjønn alene er ikke indikasjon for antikoagulasjonsbehandling (4).

Dabigatran, rivaroksaban og apiksaban er godkjent i Norge som slagforebyggende beI de randomiserte, kontrollerte studiene som lå til grunn for godkjenningen, var det lavere forekomst av både hjerneslag, systemiske embolier og alvorlige blødninger ved bruk av de nye antikoagulasjonsmidlene sammenlignet med warfarin, også i subgruppene som i tillegg brukte acetylsalisylsyre. Dette er grunnlaget for at de nye midlene nå anbefales som førstevalg ved atrieflimmer (4). Men samtidig bruk av antikoagulasjonsmidler og platehemmere innebærer ekstra blødningsrisiko, og dataene som ligger til grunn, diskuteres derfor nærmere i det følgende.

I RE-LY-studien (6), der man sammenlignet dabigatran med warfarin, var det om lag 50\% $ø k t$ risiko for klinisk relevante blødninger hos dem som fikk både platehemmer og antikoagulasjonsmiddel sammenlignet med dem som fikk kun antikoagulasjonsmiddel. Trippelbehandling, det vil si dobbelt platehemming med acetylsalisylsyre og klopidogrel i tillegg til antikoagulasjonsmiddel, doblet blødningsrisikoen i begge grupper. Det var ingen forskjell i blødningsrisiko mellom warfarin- og dabigatrangruppene ved kombinasjonsbehandling med platehemmer. Bruk av acetylsalisylsyre var den viktigste uavhengige og modifiserbare risikofaktoren for intrakranial blødning (7).

Bruk av acetylsalisylsyre sammen med nye antikoagulasjonsmidler ble også funnet å være en risikofaktor for alvorlige blødninger i ROCKET-AF-studien, der man sammenlignet rivaroksaban og warfarin (8).

I ARISTOTLE-studien, der effekten av og sikkerheten ved apiksaban ble sammenlignet med warfarin, brukte $24 \%$ av pasientene acetylsalisylsyre (9). Forekomsten av alvorlige blødninger var høyere hos dem som brukte acetylsalisylsyre i tillegg til warfarin $(3,9 \%)$ eller apiksaban $(3,1 \%)$ enn hos dem som brukte kun ett antikoagulasjonsmiddel (henholdsvis $2,7 \%$ og 1,8\%). Det var lavere risiko for både hjerneslag, systemiske emboluser og alvorlige blødninger i apiksabangruphandling ved ikke-valvulær atrieflimmer (5).

\author{
Henriette Johansen \\ Nevrologisk avdeling \\ Klinikk for kirurgi og nevrofag \\ Oslo universitetssykehus, Rikshospitalet \\ Ole-Christian Walter Rutherford \\ ole-christian.rutherford@so-hf.no \\ Medisinsk avdeling \\ Sykehuset Østfold \\ Anne Hege Aamodt \\ Nevrologisk avdeling \\ Klinikk for kirurgi og nevrofag \\ Oslo universitetssykehus, Rikshospitalet \\ David Russell \\ Nevrologisk avdeling \\ Klinikk for kirurgi og nevrofag \\ Oslo universitetssykehus, Rikshospitalet \\ og \\ Institutt for klinisk medisin \\ Universitetet i Oslo \\ Dan Atar \\ Kardiologisk avdeling B \\ Oslo universitetssykehus, Ullevål \\ og \\ Institutt for klinisk medisin \\ Universitetet i Oslo

\section{Waleed Ghanima} \\ Medisinsk avdeling \\ Sykehuset Østfold \\ og \\ Institutt for klinisk medisin \\ Universitetet i Oslo
}

Henriette Johansen og Ole-Christian Walter Rutherford har i lik grad bidratt til denne artikkelen.

> Se lederartikkel side 1505 og kronikk side 1556

Engelsk oversettelse på www.tidsskriftet.no

\section{HOVEDBUDSKAP}

Kombinasjon av nye antikoagulasjonsmidler og platehemmere er i hovedsak kun indisert ved akutt koronarsyndrom og behov for stenter i koronarkar hos pasienter med indikasjon for antikoagulasjonsbehandling grunnet atrieflimmer eller venøs tromboembolisme

Atrieflimmerpasienter som gjennomgår perkutan koronar intervensjon (PCI) og stentimplantasjon anbefales kortvarig (1-6 md.) trippelbehandling, deretter antikoagulasjonsmiddel kombinert med klopidogrel i opptil 12 måneder og så antikoagulasjonsmiddel alene

I de fleste andre tilfeller bør slik kombinasjonsbehandling unngås - på grunn av stor blødningsfare 
Figur 1 Oversikt over tilstander med indikasjon for antikoagulasjonsbehandling eller platehemming som monoterapi eller i kombinasjon

\begin{tabular}{|c|c|c|c|c|c|}
\hline Klinisk bilde & & Akutt koronarsyndrom & Stabil koronarsykdom & Hjerneinfarkt & $\begin{array}{l}\text { Hjerneinfarkt/TIA med } \\
\text { arteriestenoser og } \\
\text { stentinnlegging i pre- } \\
\text { og intracerebrale kar }\end{array}$ \\
\hline & Standardbehandling & $\begin{array}{l}\text { Acetylsalisylsyre + } \\
\text { P2Y12-hemmer }\end{array}$ & $\begin{array}{l}\text { Acetylsalisylsyre } \\
\text { monoterapi }\end{array}$ & $\begin{array}{l}\text { Acetylsalisylsyre + } \\
\text { dipyridamol eller } \\
\text { klopiogrel }\end{array}$ & $\begin{array}{l}\text { Acetylsalisylsyre + } \\
\text { klopidogrel }\end{array}$ \\
\hline Atrieflimmer & $\begin{array}{l}\text { Antikoagulasjons- } \\
\text { middel monoterapi }\end{array}$ & $\begin{array}{l}\text { Antikoagulasjons- } \\
\text { behandling og dobbelt } \\
\text { platehemming } \\
1-6 \text { måneder etter } \\
\text { stentimplantasjon, } \\
\text { etterfulgt av } \\
\text { antikoagulasjonmiddel } \\
\text { pluss klopidogrel i } \\
\text { opptil } 1 \text { år, etterfulgt av } \\
\text { antikoagulasjonsmiddel } \\
\text { som monoterapi }\end{array}$ & $\begin{array}{l}\text { Uten stentimplantasjon: } \\
\text { Antikoagulasjonsmiddel i } \\
\text { monoterapi } \\
\text { Med stentimplantasjon: } \\
\text { Antikoagulasjons- } \\
\text { middel og dobbelt } \\
\text { platehemming i } 1 \text { måned } \\
\text { etter stentimplantasjon, } \\
\text { etterfulgt av anti- } \\
\text { koagulasjonsmiddel } \\
\text { pluss klopidogrel i } \\
\text { opptil } 1 \text { år, etterfulgt av } \\
\text { antikoagulasjonsmiddel } \\
\text { som monoterapi }\end{array}$ & $\begin{array}{l}\text { Antikoagulasjon } \\
\text { monoterapi }\end{array}$ & $\begin{array}{l}\text { Antikoagulasjonsmiddel } \\
\text { og acetylsalisylsyre/ } \\
\text { klopidogrel }\end{array}$ \\
\hline $\begin{array}{l}\text { Venøs trombose } \\
\text { - initial } \\
\text { behandling } \\
\text { (første } 3 \text { md.) }\end{array}$ & $\begin{array}{l}\text { Antikoagulasjons- } \\
\text { middel monoterapi }{ }^{1}\end{array}$ & $\begin{array}{l}\text { Antikoagulasjons- } \\
\text { behandling og dobbelt } \\
\text { platehemming i 1-3 } \\
\text { måneder (metallstent) } \\
\text { eller i } 3-6^{2} \text { måneder } \\
\text { (medikamentavgivende } \\
\text { stent) }\end{array}$ & $\begin{array}{l}\text { Antikoagulasjonsmiddel } \\
\text { monoterapi }\end{array}$ & $\begin{array}{l}\text { Antikoagulasjons- } \\
\text { middel monoterapi }\end{array}$ & $\begin{array}{l}\text { Antikoagulasjonsmiddel } \\
\text { og acetylsalisylsyre og } \\
\text { klopidogrel }\end{array}$ \\
\hline $\begin{array}{l}\text { Venøs trombose } \\
\text { - sekundær- } \\
\text { profylakse } \\
\text { (behandling } \\
\text { etter } 3 \text { md.) }\end{array}$ & $\begin{array}{l}\text { Antikoagulasjons- } \\
\text { middel monoterapi }{ }^{1}\end{array}$ & $\begin{array}{l}\text { Som over ved høy risiko } \\
\text { for residiv av venøs } \\
\text { trombose, ellers dobbelt } \\
\text { platehemming uten } \\
\text { antikoagulasjonsmiddel }\end{array}$ & $\begin{array}{l}\text { Antikoagulasjonsmiddel } \\
\text { monoterapi }\end{array}$ & $\begin{array}{l}\text { Antikoagulasjons- } \\
\text { middel monoterapi } \\
\text { ved høy risiko } \\
\text { for residiv av } \\
\text { venøs trombose, } \\
\text { ellers enten } \\
\text { acetylsalisylsyre og } \\
\text { dipyridamol eller } \\
\text { klopiogrel }\end{array}$ & $\begin{array}{l}\text { Antikoagulasjonsmiddel } \\
\text { ved høy risiko for residiv } \\
\text { av venøs trombose, } \\
\text { ellers acetylsalisylsyre } \\
\text { og klopidogrel }\end{array}$ \\
\hline $\begin{array}{l}\text { Trombose- } \\
\text { profylakse } \\
\text { ved hofte-/ } \\
\text { kneprotese- } \\
\text { operasjoner }\end{array}$ & $\begin{array}{l}\text { Antikoagulasjons- } \\
\text { middel monoterapi }{ }^{3}\end{array}$ & $\begin{array}{l}\text { Vanligvis tilstrekkelig } \\
\text { med acetylsalisylsyre } \\
+ \text { P2Y12-hemmer, ev. } \\
\text { tromboseprofylakse med } \\
\text { DOAK i tillegg }\end{array}$ & $\begin{array}{l}\text { Kan fortsette med } \\
\text { acetylsalisylsyre under } \\
\text { profylaktisk behandling } \\
\text { med DOAK }\end{array}$ & $\begin{array}{l}\text { Kan fortsette med } \\
\text { acetylsalisylsyre } \\
\text { under profylaktisk } \\
\text { behandling med } \\
\text { DOAK }\end{array}$ & $\begin{array}{l}\text { Kan være tilstrekkelig } \\
\text { med acetylsalisylsyre } \\
\text { og klopidogrel, } \\
\text { eventuelt kan kortvarig } \\
\text { tromboseprofylakse gis } \\
\text { i tillegg }\end{array}$ \\
\hline
\end{tabular}

${ }^{1}$ Det anbefales 3 måneder antikoagulasjonsbehandling for pasienter med høy risiko for blødning, pasienter med leggvenetrombose og for venøs trombose utløst av forbigående årsak. For pasienter med annengangstrombose eller første idiopatisk trombose anbefales det antikoagulasjonsbehandling på ubestemt tid dersom blødningsrisikoen ikke er høy (1)

${ }^{2}$ Ved svært høyt blødningsrisiko kan man også ved medikamentavgivende stent overveie 1-6 md.

${ }^{3}$ For tromboseprofylakse gis det redusert dose antikoagulasjonsmiddel i 2-5 uker (1)

pen enn i warfaringruppen. Denne forskjellen var uavhengig av om pasientene tok acetylsalisylsyre eller ikke (10).

\section{Perifer karsykdom og cerebro- vaskulær sykdom uten atrieflimmer} Platehemmere (i denne pasientgruppen acetylsalisylsyre og klopidogrel) anbefales som profylaktisk behandling ved perifer karsykdom, ved symptomatiske carotisstenoser og andre typer hjerneinfarkt/TIA uten påvist atrieflimmer.
Det finnes foreløpig ingen randomiserte, kontrollerte studier der man har undersøkt effekt og sikkerhet ved bruk av nye antikoagulasjonsmidler i denne pasientgruppen (fig 1) $(11,12)$.

\section{Koronarsykdom}

\section{Nye antikoagulasjonsmidler}

ved akutt koronarsyndrom

Pasienter med akutt koronarsyndrom og pasienter med stabil koronarsykdom som gjennomgår stentimplantasjon behandles vanlig- vis med acetylsalisylsyre og en platehemmer i klassen P2Y12-hemmere (klopidogrel, prasugrel eller ticagrelor) i en periode, avhengig av valgt revaskulariseringsstrategi, type stent og komorbiditet/blødningsrisiko (13). Til tross for dobbelt platehemmerbehandling får allikevel en betydelig andel av pasientene nye iskemiske hendelser (ca. $10 \%$ innenfor et år) (14).

Det er velkjent at antikoagulasjonsbehandling med warfarin i tillegg til platehemmere gir færre nye iskemiske hendelser ved koro- 
narsykdom, men kombinasjonen medfører en betydelig blødningsrisiko (15). De nye antikoagulasjonsmidlenes rolle etter akutt koronarsyndrom er omdiskutert.

IAPPRAISE-II-studien ble fulldose apiksaban $(5 \mathrm{mg} \times 2)$ lagt til acetylsalisylsyre eller acetylsalisylsyre i kombinasjon med P2Y12hemmer hos høyrisikopasienter med akutt koronarsyndrom. Studien ble stoppet prematurt grunnet økt forekomst av større blødninger uten tilsvarende reduksjon $\mathrm{i}$ antall iskemiske hendelser (16).

I ATLAS-ACS 2-studien ble rivaroksaban $(2,5 \mathrm{mg} \times 2$ eller $5 \mathrm{mg} \times 2)$ lagt til acetylsalisylsyre og klopidogrel etter akutt koronarsyndrom, og man fant at rivaroksaban reduserte risikoen for det kombinerte endepunktet død av kardiovaskulære årsaker, hjerteinfarkt og hjerneslag (hasardratio 0,84). Kun den lave dosen $2,5 \mathrm{mg} \times 2$ daglig ga signifikant redusert dødelighet av alle årsaker (17).

\section{Nye antikoagulasjonsmidler}

ved akutt koronarsyndrom og atrieflimmer Den potensielle rollen for de nye midlene hos pasienter med akutt koronarsyndrom og atrieflimmer er ikke blitt undersøkt i egne studier. Det foreligger kun data fra posthocanalyser av randomiserte, kontrollerte studier av de nye midlene ved ikke-valvulær atrieflimmer samt oppfølgningsdata fra randomiserte, kontrollerte studier av nye antikoagulasjonsmidler og platehemmere ved akutt koronarsyndrom (18).

Dersom pasienter under pågående behandling med nye antikoagulasjonsmidler utvikler hjerteinfarkt med ST-elevasjon, anbefales primært perkutan koronar intervensjon (PCI) fremfor trombolytisk behandling (3). Hos pasienter med ustabil angina pectoris eller hjerteinfarkt uten ST-elevasjon anbefales det å vurdere overgang til lavmolekylært heparin i akuttfasen og at man går tilbake til de nye midlene enten etter fem dager eller eventuelt umiddelbart etter vellykket revaskularisering (13). Lavmolekylært heparin kan gis 12 timer etter siste dose av nye antikoagulasjonsmidler.

Det finnes ingen studier hvor nye antikoagulasjonsmidler kombineres med de nyere, mer potente P2Y12-hemmerne (ticagrelor og prasugrel), derfor anbefales primært acetylsalisylsyre og klopidogrel når det er aktuelt med antikoagulasjonsbehandling (warfarin eller nye antikoagulasjonsmidler) i tillegg (fig 1) (5).

\section{Nye antikoagulasjonsmidler} ved stabil koronarsykdom

Det er foreløpig ingen indikasjon for de nye antikoagulasjonsmidlene ved stabil koronarsykdom ( $>12$ md. siden akutt koronarsyndrom) alene.

Ved stabil koronarsykdom og samtidig atrieflimmer foreslås det $\mathrm{i}$ de europeiske retningslinjene antikoagulasjonsbehandling (nye antikoagulasjonsmidler eller warfarin) alene uten tillegg av platehemmer, unntatt $i$ helt spesielle tilfeller som for eksempel hovedstammestenose, dårlig stentapposisjon, kompleks bifurkasjonsstenose, førstegenerasjons stenter eller gjentatte hjerteinfarkter på tross av sekundærprofylakse (3).

\section{Venøs tromboembolisme - behandling og profylakse}

\section{Behandling av venøs tromboembolisme}

Pasienter med akutt venøs tromboembolisme (dyp venetrombose eller lungeembolisme) bør få antikoagulasjonsbehandling $\mathrm{i}$ minst tre måneder. Dersom risikoen for blødning anses som høy, anbefales det å avslutte behandlingen etter tre måneder (1) (fig 1).

I kliniske studier der man undersøkte effekten av og sikkerheten ved de nye antikoagulasjonsmidlene ved venøs tromboembolisme, tillot man kombinasjonsbehandling med nye antikoagulasjonsmidler og dobbelt platehemming (Einstein-studiene) eller acetylsalisylsyre (Amplify-, Amplify-Extension-, RECOVER-studiene). Det var økt forekomst av klinisk relevante (hasardratio 1,81) og alvorlige blødninger (hasardratio 1,50) både i rivaroksaban- og warfaringruppene i Einsteinstudien hos pasienter som i tillegg brukte acetylsalisylsyre (19). I de andre studiene ble ikke effekt og blødningsrisiko hos pasientene som brukte acetylsalisylsyre samtidig analysert.

\section{Forebyggende behandling}

hos ortopediske pasienter

Om lag $4 \%$ av deltagerne i tromboseprofylaksestudiene med dabigatran og enoksaparin hos pasienter som gjennomgikk kne- og hofteplastikk sto samtidig på acetylsalisylsyre. Posthocanalysene viste ingen signifikant økt blødningsrisiko ved tillegg av acetylsalisylsyre sammenlignet med antikoagulasjonsbehandling i monoterapi, men det var kort oppfølgingstid - kun 28-35 dager (20).

Subgruppeanalyser av RECORD-studiene viste heller ingen signifikant forskjell i blødningsrisiko mellom rivaroksaban og enoksaparin (21). Ut ifra dette virker blødningsfaren ved kortvarig bruk av et lavdosert nytt antikoagulasjonsmiddel sammen med acetylsalisylsyre å være beskjeden.

\section{Henriette Johansen (f. 1983)}

er lege i spesialisering i nevrologi og stipendiat. Forfatter har fylt ut ICMJE-skjemaet og oppgir ingen interessekonflikter.

\section{Ole-Christian Walter Rutherford (f. 1981)}

er spesialist $\mathrm{i}$ indremedisin og ansvarlig overlege ved Medisinsk overvåkning.

Forfatter har fylt ut ICMJE-skjemaet og oppgir ingen interessekonflikter.

\section{Anne Hege Aamodt (f. 1972)}

er spesialist i nevrologi, overlege og postdoktor. Hun er leder i Norsk nevrologisk forening. Forfatter har fylt ut ICMJE-skjemaet og oppgir følgende interessekonflikter: Hun har mottatt foredragshonorar fra Boehringer Ingelheim, BMS/Pfizer og Bayer Healthcare.

\section{David Russell (f. 1948)}

er spesialist i nevrologi, overlege og professor Han er leder for den cerebrovaskulære forskningen ved Oslo universitetssykehus.

Forfatter har fylt ut ICMJE-skjemaet og oppgir følgende interessekonflikter: Han har mottatt foredragshonorar fra Boehringer Ingelheim, BMS/Pfizer og Bayer Healthcare.

\section{Dan Atar (f. 1959)}

er spesialist i indremedisin og i kardiologi, overlege og professor. Han er også forsknings sjef ved Medisinsk klinikk, Oslo universitetssykehus.

Forfatter har fylt ut ICMJE-skjemaet og oppgir følgende interessekonflikter: Han har mottatt foredragshonorar fra Boehringer Ingelheim, BMS/Pfizer, Bayer Healthcare og Cardiome.

\section{Waleed Ghanima (f. 1964)}

er spesialist i indremedisin og i blodsykdommer, seksjonsoverlege ved seksjon for blodsykdommer og forskningssjef for Sykehuset Østfold.

Forfatter har fylt ut ICMJE-skjemaet og oppgir følgende interessekonflikter: Han har mottatt foredragshonorar fra Boehringer Ingelheim, BMS/Pfizer, Bayer Healthcare, Novartis og Roche.

\section{Litteratur}

1. Vandvik PO. Retningslinjer for antitrombotisk behandling og profylakse. MagicApp: Norsk selskap for trombose og hemostase, 2013. Oppdatert 17.2.2015. www.magicapp.org/app (23.2.2015)

2. Kernan WN, Ovbiagele B, Black HR et al. Guidelines for the prevention of stroke in patients with stroke and transient ischemic attack: a guideline for healthcare professionals from the American Heart Association/American Stroke Association. Stroke 2014: 45: 2160-236.

3. Lip GY. Windecker S, Huber Ket al. Management of antithrombotic therapy in atrial fibrillation patients presenting with acute coronary syndrome and/ or undergoing percutaneous coronary or valve interventions: a joint consensus document of the European Society of Cardiology Working Group on Thrombosis, European Heart Rhythm Association (EHRA), European Association of Percutaneous Cardiovascular Interventions (EAPCI) and European Association of Acute Cardiac Care (ACCA) endorsed by the Heart Rhythm Society (HRS) and Asia-Pacific Heart Rhythm Society (APHRS). Eur Heart J 2014; 35: 3155-79.

4. Camm AJ, Lip GY, De Caterina R et al 2012 focused update of the ESC Guidelines for the management of atrial fibrillation: an update of the 2010 ESC Guidelines for the management of atrial fibrillation - developed with the special contribution of the European Heart Rhythm Association. Europace 2012: 14: 1385-413.

5. Helsedirektoratet. Informasjon om warfarin og de nye perorale antikoagulasjonsmidlene dabigatran rivaroksaban og apixaban. 
https://helsedirektoratet.no/publikasjoner/ informasjon-om-warfarin-og-de-peroraleantikoagulasjonsmidlene-dabigatranrivaroksaban-og-apixaban (23.6.2016).

6. Connolly SJ, Ezekowitz MD, Yusuf S et al. Dabigatran versus warfarin in patients with atrial fibrillation. N Engl J Med 2009: 361: 1139-51.

7. Hart RG, Diener HC, Yang S et al. Intracranial hemorrhage in atrial fibrillation patients during anticoagulation with warfarin or dabigatran: the RE-LY trial. Stroke 2012; 43: 1511-7.

8. Savelieva I, Camm AJ. Practical considerations for using novel oral anticoagulants in patients with atrial fibrillation. Clin Cardiol 2014; 37: 32-47. . eng.

9. Granger $\mathrm{CB}$, Alexander JH, McMurray JJ et al. Apixaban versus warfarin in patients with atrial fibrillation. N Engl J Med 2011; 365: 981-92.

10. Alexander JH, Lopes RD, Thomas L et al. Apixaban vs. warfarin with concomitant aspirin in patients with atrial fibrillation: insights from the ARISTOTLE trial. Eur Heart J 2014; 35: 224-32.

11. Legehåndboka. Karotisstenose 2014. Oppdatert 1.11.2014. http://nevro.legehandboka.no/ handboken/sykdommer/cerebrovaskularesykdommer/sykdommer-og-symptomer/ karotisstenose/ (6.5.2015)

12. Whayne TF. A review of the role of anticoagulation in the treatment of peripheral arterial disease. Int J Angiol 2012; 21: 187-94.

13. Windecker S, Kolh P. Alfonso F et al. 2014 ESC/ EACTS guidelines on myocardial revascularization. Rev Esp Cardiol (Engl Ed) 2015; 68: 144

14. Lane DA, Raichand S, Moore D et al. Combined anticoagulation and antiplatelet therapy for high- risk patients with atrial fibrillation: a systematic review. Health Technol Assess 2013; 17: 1-188.

15. Hurlen M, Abdelnoor M, Smith P et al. Warfarin, aspirin, or both after myocardial infarction. N Engl J Med 2002; 347: 969-74.

16. Alexander JH, Lopes RD, James S et al. Apixaban with antiplatelet therapy after acute coronary syndrome. N Engl J Med 2011; 365: 699-708.

17. Mega JL, Braunwald E, Wiviott SD et al. Rivaroxaban in patients with a recent acute coronary syndrome. N Engl J Med 2012: 366: 9-19.

18. Ghanima W, Atar D, Sandset PM. Nye perorale antikoagulasjonsmidler - en oversikt. Tidsskr Nor Legeforen 2013; 133: 1940-5.

19. Davidson BL, Verheijen S, Lensing AW et al. Bleeding risk of patients with acute venous thromboembolism taking nonsteroidal anti-inflammatory drugs or aspirin. JAMA Intern Med 2014; 174 947-53.

20. Friedman RJ, Kurth A, Clemens A et al. Dabigatran etexilate and concomitant use of non-steroidal anti-inflammatory drugs or acetylsalicylic acid in patients undergoing total hip and total knee arthroplasty: no increased risk of bleeding. Thromb Haemost 2012; 108: 183-90.

21. Ruff CT, Giugliano RP, Braunwald E et al. Comparison of the efficacy and safety of new oral anticoagulants with warfarin in patients with atrial fibrillation: a meta-analysis of randomised trials. Lancet 2014; 383: 955-62.

Mottatt 21.12. 2015, første revisjon innsendt 3.6. 2016, godkjent 23.6. 2016. Redaktør: Martine Rostadmo.

\section{Nye opplysninger}

Etter godkjenning av manuskriptet er det blitt publisert (27.8.2016) nye retningslinjer fra European Society of Cardiology (ESC) for behandling av pasienter med atrieflimmer (1). Disse inneholder noen få endringerianbefalingene for slagforebygging ved atrieflimmer. Spesielt er det viktig å notere seg at det nå foreligger en mer nyansert anbefaling i forhold til $\mathrm{CHA}_{2} \mathrm{DS}_{2}$-VASc-skår (kvinner med bare én tilleggsrisikofaktor har fătt en nedgradert anbefaling - klasse lla istedet forklasse I). Artikkelen må derfor leses og tolkes i lys av disse nye anbefalingsgraderingene.

\section{Litteratur}

1. Kirchhof P, Benussi S, Kotecha D et al. 2016 ESC Guidelines for the management of atrial fibrillation developed in collaboration with EACTS: The Task Force for the management of atrial fibrillation of the European Society of Cardiology (ESC)Developed with the special contribution of the European Heart Rhythm Association (EHRA) of the ESCEndorsed by the European Stroke Organisation (ESO). Eur Heart J 2016. E-publisert 27.8. 